\title{
Approaches to Measuring and Forecasting Remote Employment
}

\author{
K. V. Yankov* \\ Institute of Economic Forecasting, Russian Academy of Sciences, Moscow, Russia \\ *e-mail: kirill_yankov@mail.ru \\ Received February 1, 2021; revised February 8, 2021; accepted March 2, 2021
}

\begin{abstract}
The article proposes approaches to the definition of terms in the field of remote employment, discusses the feasibility of collecting data on this phenomenon, and its forecasting. The system of indicators characterizing remote employment is substantiated, taking into account the available quantitative information. Based on the latest domestic and foreign publications, a methodological approach to determining the potential of remote employment, which is a key element of the forecast, is proposed.
\end{abstract}

Keywords: remote employment, remote work, coworking, forecasting

DOI: $10.1134 /$ S107570072104016X

Over recent years, researchers have increasingly observed the growth in remote employment, which implies the use of modern information and telecommunication technologies. The "Strategy for the Spatial Development of the Russian Federation for the Period up to 2025" approved in 2019 states that "remote forms of labor activity are in the ascendant." 1 This phenomenon received a powerful impetus for further development in the context of the 2020 pandemic. Forecasting remote employment is not only of theoretical but also of great practical importance. Firstly, it is necessary for forecasting and long-term planning of the settlement system, including both planning the placement of social and engineering infrastructure, and the development of a housing type that can serve as a workplace (for example, by the end of 2020, construction companies began to advertise apartments with "coworking space" 2 in the housing section). Secondly, it is required for planning the development of transport infrastructure since remote employment directly affects the parameters of commuting and mobility of the population as a whole. Thirdly, remote employment affects the parameters of the socioeconomic development of territories, since an employee can live and work in a municipality or a federal entity different from that in which the employer is taken into account by the statistics. It can

\footnotetext{
${ }^{1}$ The strategy for the spatial development of the Russian Federation for the period up to 2025, approved by the Decree of the Government of the Russian Federation of February 13, 2019 No. 207-r.

2 Here in after, "coworking space" means a location (premises) where you can rent a place to work using personal computing equipment (computer or mobile device) for the required period, both short (several hours) and long.
}

be said that remote employment affects the spatial development of the country as a whole.

Unfortunately, one cannot but agree with V. Sautkina that "the reliability degree of data on the real volumes of remote employment is questionable, since information about work that is done online, outside regulated markets, remains largely unaccounted for in the official market statistics" [1]. The forecast for the growth of remote employment in Russia so far boils down to a statement by the Minister of Labor and Social Protection, A. Kotyakov, that "after the lifting of restrictive measures due to the spread of the coronavirus, about $5 \%$ of Russia's residents will continue to work remotely." 3

Therefore, the task of obtaining a reliable quantitative estimate of the existing remote employment should be handled simultaneously with the task of its forecasting. Since in Russia the main institution for the development of such an assessment is state statistics, first of all, it is necessary to determine the indicators that could be subject to statistical observation. Such indicators should take into account both the legal framework and the economic characteristics of remote employment and contribute to more reliable forecasting. Certainly, in this case, one should look for different, alternative methods of assessing the considered phenomenon.

Approaches to the definition of remote employment and specific features of its types. Meanwhile, the very concept of "remote employment" has not received an unambiguous scientific interpretation. The terms

\footnotetext{
${ }^{3}$ The Ministry of Labor and Social Protection predicted the number of persons remaining to work remotely: https://rossaprimavera.ru/news/3c1be38d.
} 
"remote working," "flexible workplace," "mobile work" etc. are often used as its synonyms.

As is the case with some terms, remote employment can be understood in different ways in economic and legal sciences. Actually, legal science (labor law) has long known the institution of "work from home," and in 2020 a federal law On Amendments to the Labor Code... ${ }^{4}$ was adopted, dedicated to the regulation of "distance (remote) work." Remote work is defined in it as "the performance of a labor function defined by an employment contract outside the location of the employer, its branch, representative office, other separate structural unit (including those located in another locality), outside a stationary workplace, territory or facility directly or indirectly under the control employer, subject to the use of information and telecommunication networks, including the Internet, and public communication networks for the performance of this labor function and for the implementation of interaction between the employer and the employee on issues related to its implementation."

Further, the term distance (remote) work is used in the meaning determined by the Federal Law On Amendments to the Labor Code... ${ }^{4}$. The term remote employment is used in a broader sense, including those remote forms of performing work occupations that are not covered by the term distance (remote) work.

Rosstat, in turn, takes into account the work "on the basis of an employment contract for the performance of work at home using the Internet (remote work). ${ }^{5}$ At the same time, in the annual sample survey of the labor force for 2019 (there are no such data in quarterly surveys), out of 67.1 million employed (total) teleworkers, only 30 thousand (less than $0.05 \%$ ) were identified. One has to agree that this "only poorly and inadequately reflects the actual situation"6.

In the scientific literature, remote (distance) employment (work) is defined in different ways. Thus, in the legislation on making these amendments to the Labor Code, the definition of Slepov supported by Malyshev [2] is: "Remote work means the performance of a labor function defined by an employment contract outside the location of the employer, its branch, representative office, other separate structural unit (including those located in another locality), as well as outside a stationary workplace, territory or facility directly or indirectly under the control of the employer" [3]. The definition offered by Orlov and

\footnotetext{
${ }^{4}$ Federal Law No. 407-FZ of 08.12.2020, On Amendments to the Labor Code of the Russian Federation Regarding the Regulation of Distance (Remote) Work and Temporary Transfer of an Employee to Distance (Remote) Work on the Initiative of the Employer in Exceptional Cases.

52019 Labor Force Survey, Table 3.9 Employees aged 15 and over by actual number of hours worked per week in main job and type of contract. https://rosstat.gov.ru/compendium/document/13265.

${ }^{6}$ Remote work now and in 2021: what the labor code says. https://habr.com/ru/company/habr_career/blog/520320/.
}

Buranshina: "Remote work is the practice of organizing a work process, in which permanent or temporary employees work at home, instead of going to work at the premises of the employer or customer" [4] appears somewhat outdated since it fails to cover the use of "coworking spaces."

There is no consensus on the relationship between remote employment and freelancing. In a number of works [1, 5], these concepts are almost identical. However, one should agree with Orlov and Buranshina that "the remote worker and the freelancer are completely different roles." A freelancer for a company is a performance-based provider. He works under civil law contracts. A freelancer is not a member of the staff and does not have access to corporate information resources. Unlike freelancers, remote workers are full-time employees" [4].

Obviously, indicators that quantitatively characterize remote employment can only be developed based on its unambiguous definition. Since the indicators should, whenever possible, become the object of state statistical observation, and the needs of the state (rather than science) are decisive for statistics, it is advisable to take the definition of distance (remote) work established by law as a baseline. Surely, this does not rule out a discussion about a different definition of the considered concept from the viewpoint of economic science.

It should be noted that the definition established by the law expands the concept of remote work in comparison with the one used by Rosstat at present. First, while Rosstat takes into account work only performed at home, the law interprets as remote any work performed "outside a stationary workplace, territory or facility, directly or indirectly under the control of the employer." In addition to home premises, work is increasingly carried out using coworking spaces [6, 7], and in the warm season, work is possible in parks, squares, and other public areas. Second, while Rosstat takes into account the work "using the Internet," the law expands this qualifying feature, speaking of the use of "information and telecommunication networks, including the Internet, and public communication networks."

The definition of remote work established in the law does not cover all possible types of remote employment. First of all, this is the aforementioned home-based work, the term appearing both in the studies of the Soviet economy and in Soviet labor legislation: it is still regulated by different norms of the Labor Code. Traditionally, such work does not require either the Internet or other communication networks, the use of which, according to the law, is a qualifying feature of remote work. Although the Labor Code distinguishes home-based work from remote work, one should pay attention to the opinions of legal scholars: for example, Motsnaya believes that home-based work is a kind of remote employment [8]. From the eco- 
nomic viewpoint, these types of labor differ insignificantly, nevertheless, many things bring them together, primarily, the impact on the settlement system and on the load of the transport infrastructure.

In order to more accurately assess the impact of remote employment on socioeconomic development, a distinction should be made between fully remote and partially remote employment. With fully remote employment, an employee's visit to the employer is not envisaged and the distance between the places of their location, as a rule, does not matter. At the same time, there is no shuttle migration, and the transport infrastructure is not used for this purpose (except for cases when the employee does not work at home, but in some coworking space remote from home).

With partial remote employment, the employee does not visit the workplace every day. The shuttle labor migration takes on a specific character, and the limits of possible distance from the place of residence to the workplace are expanding (a certain analogy can be drawn with a working arrangement for an employee "24-hour workday after a three-day streak"). Thus, the impact of the increasing variety in different types of remote work both on the settlement system and on the load of the transport infrastructure differs significantly, and this should be taken into account when developing indicators.

Remote employment is quite clearly delimited from other forms of territorial dispersal of jobs [9]. As noted above, it does not include freelancing, or work under civil contracts (which, however, in terms of its economic content is often indistinguishable from hiring, while having a different legal form). In addition, it does not include work in departments that are remote from the main location of the organizations. The task of statistical accounting and forecasting of these phenomena also remains relevant.

Quantitative assessment of remote employment and development of the indicator system. In recent years, several fairly successful attempts have been made to estimate the spread of remote employment. In Russia, a so-called census of freelancers was carried out [5], and scientists from the University of Oxford developed the OLI (Online Labor Index) $[10]^{7}$, based on data from English-language Internet labor platforms (services for job offer and search). Despite the shortcomings (remote workers and freelancers are combined, other ways of finding workers are not taken into account, the assessment does not include the transfer of existing workers to remote mode), the OLI index reasonably well shows the dynamics of demand for remote work, including a sharp increase in such demand during the period of pandemics. In Russian Internet services, a similar growth was also noted (for example, "according to the estimates of hh.ru recruit-

\footnotetext{
${ }^{7}$ Introducing the labor project. URL: https://ilabour.oii.ox.ac.uk/.
}

ment platform, at the beginning of 2020, vacancies with a remote work format accounted for about $2 \%$ of all offers, by the end of the year their share had doubled and amounted to 4-5\%" [11]), however, when applying a similar assessment method in Russia, it is necessary to take into account the ratio of different ways employed for headhunting, along with Internet recruitment services.

For statistical observation, as a basic indicator that quantitatively characterizes remote employment, it is advisable to take the number of distance (remote) workers, as determined by the federal legislation. In addition to the decomposition of the indicator by occupation, types of economic activity and territories, the following aspects should be distinguished in its composition:

-The number of employees working completely remotely and working partially remotely. For the latter, it is advisable to calculate the share of working time attributable to remote work in the total working time and the average number of trips to work per week.

-The number of employees regularly using coworking spaces for remote work.

As an additional indicator, it appears feasible to use the headcount of other persons working remotely (homeworkers), also with a decomposition by occupation, type of economic activity, and territory.

The practical significance of statistical data on remote employment will be much higher if they are aggregated not only by federal subjects but also by smaller territorial units (administrative regions, municipalities).

The question of whether information resources at the disposal of state bodies can be useful for assessing remote employment deserves special discussion. Thus, the Federal Tax Service and the Pension Fund have information about both the workplace and the place of registration at the domicile of each legally working Russian. But the remoteness of the domicile from the workplace in itself does not indicate the remote nature of work (for example, people often actually live not at the place of their permanent registration, or the workplace is not located at the legal address of the employer); in addition, one can work remotely while living close to the employer. However, in the event that each employer begins to indicate in the reporting the nature of each employee's work (regular or remote), comparison with the available data on places of residence will provide impersonal information on the geographical distribution of remote workers. This will make it possible, in particular, to make a much more accurate assessment of the socioeconomic situation in the territories of residence of the remotely employed, which the local authorities do not actually "see" as employed.

Assessment of remote employment potential. Distinction should be drawn between estimating the assessable existing size of remote employment and its maxi- 
mum possible potential (marginal level), the value of which is influenced by a number of factors. The least difficult seems to assess the period for which the influence of the factors presented below is known. Forecasting the marginal level for more distant periods seems to be a more challenging task, and the accuracy of such a forecast for the long term is still low.

The main factor limiting the spread of remote employment is the development of technologies, which determines the possibility (or impossibility) of performing certain labor operations remotely. Therefore, the most accurate estimate of the upper limit on the share of remote workers can be obtained by analyzing this possibility for each occupation (job).

In 2020, new studies on remote employment were published abroad. Thus, Dingel and Neiman [12] in their study based on surveys of workers in about 1000 occupations in the United States, estimated the proportion of jobs that can be performed at home; for the United States it was $37 \%$. Based on the data of the International Labor Organization on the structure of professional employment in different countries of the world, they assessed this value for a number of countries; for Russia, their estimate was $34 \%$. This work also revealed a direct relationship between GDP per capita (PPP-adjusted) and the share of jobs that can be performed at home. The work of European authors [13] assessed the potential of remote work for the countries of the European Union (as well as the United States, Switzerland, and Turkey) differentially for large agglomerations, small towns, and rural areas, and also revealed a direct dependence of the remote employment potential on the share of workers with higher education. The application of this approach to Russia (taking into account the size of GDP per capita and the share of workers with higher education, $33.7 \%^{8}$ ) gives an approximate estimate of the potential share of remote workers in the range from $30 \%$ (rural areas) to $40 \%$ (Moscow agglomeration).

The method used by American researchers seems to be applicable to determining the potential of remote employment but it should be supplemented by taking into account other limiting factors, besides technological. To assess the potential of remote employment in Russia, it is advisable to use the All-Russian Classifier of Occupations ${ }^{9}$, while there is no need to thoroughly examine all types of occupations: thus, it is obvious that a bricklayer (code 7112) or a window cleaner (code 9123) cannot work at home (or in a coworking space), and a writer (code 2641) can. However, for some occupations (at least those that are relatively common), the possibility of remote work needs to be

\footnotetext{
82019 Labor Force Survey, Table 6.4, Labor force structure aged 15 and over by educational level. https://rosstat.gov.ru/compendium/document/13265.

9 ARC 010-2014 (ISCO-08). All-Russian classifier of occupations (adopted and put into effect by the Order of Rosstandart dated 12.12.2014 No. 2020-st).
}

studied: for example, can employees of contact information centers (code 4222) work from home, or does the technology require their working in a contact center room?

From the types of occupations, it is also possible to take into account those that have the potential for both distance and home work. Thus, the marginal level of remote employment for these types can be assessed separately.

There are also developments in forecasting the structure of employment: as pointed out by Korovkin and Korolev, "the experience of predictive and analytical studies of the dynamics in the employment sector and the labor market ... makes it possible to make an inertial assessment of the structure of the employed population by the types of occupation" [14]. At the same time, it is necessary to take into account the rapid development of science and technology, which involves the emerging possibility of remote equipment operation. Thus, in the future, it might be possible that the "operator of motorized agricultural equipment" (code 8341) will be able to drive a tractor or a combine harvester from his home. Therefore, in the mid- and long-term forecasting of remote employment, it is crucial to take into account forecasts of scientific and technological development.

Less accurate, but at the same time much less labor-intensive, is assessing the potential of remote employment using groups of occupations rather than individual jobs. Rosstat, according to the results of sample surveys of the labor force, has data on the number of employees in 34 groups of occupations ${ }^{10}$.

In addition to technological factors, there are other factors that limit the potential for remote employment. Out of these, the most important appears to be the unwillingness of workers to work remotely. According to an analytical report by VTsIOM and the Social Business Group, among those who were forced to switch to remote employment in the spring of 2020 , $61 \%$ rated their transition experience negatively, and only $36 \%$ positively. ${ }^{11}$ The motives of negative assessment can be divided into surmountable (for example, "a large amount of work," "poor quality of the Internet") and based on deep psychological reasons ("tired of sitting at home," "working better in a team," "it is necessary to separate home and office").

Another important issue is the decrease in the quality of remote work in comparison with the usual working arrangement. Thus, Dingel and Neiman in terms of technology highly estimate the potential of remote work in the field of education (Education, Training): $0.85-0.98$ (with a maximum of 1.0) [12]. The transfer of the educational system at the spring peak of the

\footnotetext{
${ }^{10}$ Labor resources. https://rosstat.gov.ru/labour_force.

${ }^{11}$ Joint analytical report by VTsIOM and Social Business Group. https://wciom.ru/analytical-reports/analiticheskii-doklad/czifrovaya-gramotnost-i-udalennaya-rabota-v-usloviyakh-pandemii.
} 
pandemic to distance learning in Russia is consistent with these values, but at the same time, this involved a commonly recognized inferior quality of such education [15]. Therefore, for certain socially important types of occupation (for example, in education, culture, etc.), in addition to the technological limitation of their potential, it is necessary to determine such a level of remote employment, at which the quality would remain at a socially acceptable level.

One should also highlight the factor of state restrictions that do not allow transferring many workers to remote work even if it is technically possible. For example, workers serving the population in the multifunctional centers "My Documents" could receive citizens remotely, but the state purposefully provides an opportunity for citizens to communicate with them personally. Requirements for the personal presence of workers are mandatory for many security-sensitive occupations. Logically, there should be two levels of state restrictions: for a normal situation and for a situation of imposing restrictions for a special period caused by an emergency situation and similar legal regimes (including the high alert regime introduced in the regions of Russia in 2020 in the context of the coronavirus pandemic).

Separately, one should single out such a limitation as housing conditions that do not allow a remote worker, for example, to use a separate room for his work. On average, there is a little more than one room per person in Russia ${ }^{12}$, the same as in Turkey and Mexico (2.4 rooms in the United States) [16]. And from 2005 to 2019 , the average size of a newly built apartment in Russia decreased from 84.5 to 73.2 sq. m, i.e., by almost $14 \%^{13}$.

There are other, less common factors limiting the growth in remote employment (for example, the inability to ensure information security).

It appears that the above factors limiting the potential of distance employment apply to both fully and partially remote employment (the exception may be situations in which the employee's duties include performing different labor functions on different days). However, partly remote employment can be more attractive for a significant part of employees than completely remote working, since it allows them to maintain a sense of belonging to the team, develop social ties, etc.

Out of the main specified factors, three are individual (technological, quality deterioration, and government restrictions), i.e., their impact is differentiated by type of occupation, and each of them must be taken

\footnotetext{
${ }^{12}$ The author's calculations were made on the basis of the table "Main indicators of housing conditions of the population." https://rosstat.gov.ru/folder/13706

${ }^{13}$ The author's calculations were made on the basis of the tables "Number of apartments built and their average size": Construction in Russia. Stat. Sat. M .: Rosstat, 2016. S. 863; Construction in Russia. Stat. Sat. M .: Rosstat, 2020. p. 863.
}

into account when assessing the marginal level of remote employment for a specific type of occupation. As for the rest of the factors (reluctance of workers and housing conditions), it can be assumed that they affect all types of employment in equal measure, and can be taken into account using reducing factors.

It appears practically feasible to assess two levels of remote employment potential, i.e.:

The gross potential shows the maximum possible level of remote employment, which can practically be achieved only in a special period. Out of all the constraints, it only considers technological constraints. Its assessment is practically significant, first of all, for the planning of life support and economic activity in special periods.

The net potential shows the economically justified level of remote employment for an ordinary situation and takes into account all the above restrictions. It is advisable to use its estimates for forecasting economic development and planning the development of infrastructure in general.

The procedure for assessing the potential of remote employment may include the following:

Step 1. Formulation of requirements for the mathematical accuracy of the assessment.

Step 2. Identifying the set of studied types (groups) of occupations (with the exception of types that, due to the small number of employees, do not affect the accuracy).

Step 3. Categorizing the selected types (groups) of occupations into: a) definitely not suitable for remote work; b) definitely suitable for remote work; c) requiring further study.

Step 4. Studying each occupation type (group) of category (c) taking into account individual limiting factors, with the determination of a coefficient from 0 (remote work is not possible) to 1 (remote work is possible for all employed during the entire working time).

Step 5. For assessing the net potential, the reducing coefficients $P$ (for reasons of unwillingness to work remotely) and $R$ (for reasons of unsatisfactory housing conditions) should be estimated based on sociological research and expert assessments.

Step 6. Estimating the gross potential of remote employment by formula (1):

There are $N$ types of occupations (jobs): $I=1,2, \ldots, N$.

Each (ith) type (group) of occupations corresponds to:

$k_{i}$-the level of potential for remote work (in the range from 0 to 1 ) for a given type (group) of occupations.

$k_{i}=0$-this occupation (group of occupations) is utterly unsuitable for remote work.

$k_{i}=1$ all those engaged in this occupation (group of occupations) can use the remote work arrangement.

$v_{i}$-the number of those engaged in the $i$ th occupation (group of occupations). 
Table 1. Calculation of the potential of remote employment by occupation group

\begin{tabular}{|c|c|c|}
\hline Occupation group & $\begin{array}{l}\text { Value of the coefficient } k_{i} \\
\text { for the occupation group }\end{array}$ & $\begin{array}{l}\text { Number of the employed, } \\
\text { thousand people }\end{array}$ \\
\hline Executive officers & 0.87 & 4354 \\
\hline Health care professionals & 0.05 & 1606 \\
\hline Education professionals & 0.98 & 4363 \\
\hline Business and administration professionals & 0.87 & 4867 \\
\hline $\begin{array}{l}\text { Information and communication technology (ICT) } \\
\text { specialists }\end{array}$ & 1.00 & 986 \\
\hline Specialists in the field of law, humanities and culture & 0.84 & 2920 \\
\hline Nursing health personnel & 0.05 & 2566 \\
\hline $\begin{array}{l}\text { Secondary specialized personnel for economic and } \\
\text { administrative activities }\end{array}$ & 0.65 & 3464 \\
\hline $\begin{array}{l}\text { Mid-level specialized personnel in the field of legal, social } \\
\text { work, culture, education, sports and related activities }\end{array}$ & 0.37 & 832 \\
\hline ICT technicians & 0.65 & 159 \\
\hline Employees of general and service office equipment & 0.65 & 553 \\
\hline Public service employees & 0.28 & 560 \\
\hline Other office workers & 0.65 & 366 \\
\hline Personal service workers & 0.26 & 2676 \\
\hline Salespersons & 0.28 & 5431 \\
\hline Personal care workers & 0.26 & 890 \\
\hline $\begin{array}{l}\text { Employees of services providing protection of citizens } \\
\text { and property }\end{array}$ & 0.06 & 2283 \\
\hline $\begin{array}{l}\text { Skilled workers in agriculture, forestry, fish farming, and } \\
\text { fisheries }\end{array}$ & 0.01 & 1742 \\
\hline Construction and related workers (excluding electricians) & 0.00 & 2358 \\
\hline $\begin{array}{l}\text { Metalworking and mechanical engineering workers, } \\
\text { mechanics and repairmen }\end{array}$ & 0.01 & 3963 \\
\hline Crafts and printing workers & 0.01 & 255 \\
\hline Electrical and electronics workers & 0.01 & 1120 \\
\hline Food, wood, textile, garment and related workers & 0.01 & 1965 \\
\hline Operators of industrial plants and stationary equipment & 0.01 & 2272 \\
\hline Assembling fitters & 0.01 & 211 \\
\hline Drivers and operators of mobile equipment & 0.03 & 6795 \\
\hline Maintenance crew and cleaners & 0.00 & 1212 \\
\hline $\begin{array}{l}\text { Unskilled workers in agriculture, forestry, fish farming, } \\
\text { and fishing }\end{array}$ & 0.01 & 385 \\
\hline $\begin{array}{l}\text { Unskilled workers in mining, construction, manufac- } \\
\text { turing, and transportation }\end{array}$ & 0.01 & 1498 \\
\hline Cooking assistants & 0.00 & 139 \\
\hline Trash collection workers and other unskilled workers & 0.00 & 2365 \\
\hline
\end{tabular}

Source: Author's calculations based on data from Rosstat "Labor resources." https://rosstat.gov.ru/labour_force; [12]. 
$K$-the level of potential for remote work for those engaged in all (groups) of occupations:

$$
K=\left(\sum_{i=1}^{N} k_{i} v_{i}\right) / \sum_{i=1}^{N} V_{i} .
$$

If for $v_{i}$ we take not the number of those engaged (employed) but their proportion (from 0 to 1 ), then

$$
K=\sum_{i=1}^{N} k_{i} v_{i}
$$

Net potential can be estimated by the formula:

$$
K=\left[\left(\sum_{i=1}^{N} k_{i} V_{i}\right) / \sum_{i=1}^{N} V_{i}\right] P R .
$$

We believe that this algorithm can be used at the level of both the entire country and individual territories. At the same time, steps $1-5$ can only be performed at the country level, and the potential for remote employment in certain territories (in federal subjects, agglomerations, and municipalities) will differ due to the different structure of employment. With the accumulation of information, individual coefficients for the type of employment and general reducing coefficients can be differentiated both by territory and by type of settlement (large city/small town/rural area).

In order to test the proposed algorithm, we calculated the gross potential for groups of occupations for Russia. Determining the values of the remote employment potential for 65155000 jobs out of 71933000 $(90.6 \%$, or for 31 groups out of 35$)$ is rather laborious which prompted us to adopt the coefficients obtained in the American labor market by Dingel and Neiman [12] (Table 1).

The calculated value of the gross potential for remote employment in Russia is $34.2 \%$. As for the net potential, the determination of the reducing coefficients $P$ and $R$ by expertise at the level of $40-45 \%$ allows us to estimate it at the level of $14-15 \%$.

At the first stage, the assessment of the net potential for remote employment can be conventionally taken as its forecast value in the medium term (35 years). Subsequently, when a time series of statistical indicators is available, the forecast can be refined taking into account the dynamics of the current indicators.

Before the appearance of statistical data, it is advisable to assess the existing level of remote employment using other methods: according to data from Internet services for job searches or employers' surveys (similar to surveys on the interest of enterprises in remote divi- sions [17]). It would also be useful to check on Russian data the hypotheses put forward by foreign researchers about the direct relationship of remote employment with GDP (using the example of the GRP of Russian regions) and with the share of workers with higher education. Confirmation of such dependences, as well as the identification of new ones, will make it possible to obtain more accurate forecast estimates for individual territories.

Long-term forecasting of remote employment is inseparable from forecasting scientific and technological development. Basically, both the entire employment of the population and its structure depend on scientific and technological progress.

\section{REFERENCES}

1. V. A. Sautkina, "Virtual employment: new opportunities and risks," Sots.-Tr. Issled., No. 2, 59 (2020).

2. A. A. Malyshev, "Management problems of organizing remote work," Vektor Ekon., No. 4, 13 (2020).

3. A. V. Slepov, "Remote work. How to transfer office employees to remote work," Tr. Spory, No. 6 (2013). https://e.tspor.ru/313592. Accessed January 25, 2021.

4. V. B. Orlov and E. I. Buranshina, "Remote work as a new reality of labor relations: Analysis of the factors of predisposition to remote work," Vestn. Yugorsk. Gos. Univ., No. 4, 40-46 (2014).

5. D. O. Strebkov, A. V. Shevchuk, and M. O. Spirina, Development of the Russian-Speaking Market for Remote Work, 2009-2014 (Based on the Results of the Freelance Census)) (Vyssh. Shk. Ekon., Moscow, 2015) [in Russian].

6. S. S. Muradyan, "Coworking: A model of a modern office," in Young Scientists in Solving Current Problems of Science. All-Russian Scientific and Practical Conference (with International Participation): Collection of Articles by Students, Graduate Students, and Young Scientists (Krasnoyarsk, 2016), pp. 261-263.

7. A. O. Knyazeva, "Development of coworking in Russia. Problems and prospects," in Current Management: Vectors of Development. Collection of Scientific Papers of the International Scientific and Practical Conference (Saratov, 2018), pp. 64-66.

8. O. V. Motsnaya, "Atypical forms of employment," Vopr. Tr. Prava, No. 8, 41 (2009).

9. K. V. Yankov, "Territorial workspace dispersion as a factor of the spatial development of the economy," Stud. Russ. Econ. Dev. 29 (1), 50-55 (2018).

10. O. Kässi and V. Lehdonvirta, Online Labour Index: Measuring the Online Gig Economy for Policy and Research (August 21, 2018). Technological Forecasting and Social Change, Forthcoming. https://ssrn.com/abstract $=3236285$. Accessed January 25, 2021.

11. M. Tirskaya, "Petersburgers massively look for parttime jobs and wait for aid," RBC, Jan. 2 (2021). https://www.rbc.ru/spb_sz/02/01/2021/5fe46c3b9a79476021043865. Accessed January 24, 2021. 
12. J. I. Dingel and B. Neiman, How Many Jobs Can Be Done at Home? CEPR Discussion Paper No. DP14584 (2020). https://ssrn.com/abstract $=3594206$. Accessed January 24, 2021.

13. C. Özgüzel, P. Veneri, and R. Ahrend, "Potential for remote working across different places," VoxEU, July 15 (2020). https://voxeu.org/article/potential-remoteworking-across-different-places. Accessed January 23, 2021.

14. A. G. Korovkin and I. B. Korolev, "Perspective dynamics of employment by occupation," in Strategic Planning and Development of Enterprises. Materials of the Sixteenth All-Russian Symposium, Ed. by G. B. Kleiner (TsEMI, Moscow, 2015), pp. 82-84.
15. E. V. Grunt, E. A. Belyaeva, and S. Lissitsa, "Distance education in a pandemic: New challenges to Russian higher education," Perspekt. Nauki Obraz., No. 5, 4558 (2020).

16. "Where and how Russians live today," Vedomosti, May 16 (2018). https://www.vedomosti.ru/partner/articles/2018/05/16/769674-rossiyane-menyayut. Accessed January 25, 2021.

17. D. B. Kuvalin, A. K. Moiseev, and P. A. Lavrinenko, "Russian enterprises in spring 2017: Slow restoration of investment activity against a background of economic stabilization,” Stud. Russ. Econ. Dev. 28 (6), 672-683 (2017).

Translated by I. Pertsovskaya 